\title{
Neoconservadorismo e a ofensiva contra as religiões de matriz africana no Brasilı
}

\author{
Neoconservatism and the attacks against Afro-Brazilian Religions \\ João Bosco Hora Góis* \\ Kamila Cristina da Silva Teixeira**
}

\begin{abstract}
RESUMO: Neste trabalho buscamos mostrar como o neoconservadorismo é parte de um processo mais amplo que inclui componentes econômicos e sociais. Sublinhamos a sua dimensão religiosa e tentamos mostrar como ele vem afetando as religiões de matriz africana. Ao mesmo tempo, explicamos como os seus ataques criaram uma resposta relativamente potente por parte daqueles que são afetados por ele. Concluímos este trabalho associando as práticas religiosas neoconservadoras com um risco significativo para o Estado laico e para a democracia.
\end{abstract}

Palavras-chave: neoconservadorismo; religiões afro-brasileiras; Estado laico

ABSTRACT: In this paper we seek to show how neo-conservatism is part of a broader process that includes economic and social components. We highlight its religious face and try to show how it has been affecting the afro-Brazilian religions. At the same time, we explain how its attacks have created a somehow powerful response from those affected by it. We conclude this paper by associating new-conservatist religious practices with a significant jeopardy for lay State and democracy. Keywords: neo-conservatism; afro-Brazilian religions; lay State

\section{1 - Introdução}

A onda neoconservadora que assola diferentes países tem suas bases na crise do capitalismo e nas transformações operadas pelo capital a partir da década de 1970, as quais vêm gerando consequências negativas para a vida humana, para a natureza e para o mundo do trabalho (SANTOS, 2007; BARROCO, 2011). Assim, ela é indissociável do padrão de acumulação, denominado por Harvey (2009) de "acumulação flexível", que emergiu como resposta à crise do fordismo/keynesianismo. Este modelo, ao reestruturar a produção com o surgimento de novos setores, novas tecnologias e a introdução de novas formas de gestão da força de trabalho, reestruturou as condições e relações de trabalho tanto nos países do norte, quanto nos do sul global. Com isso, houve a expulsão de contingentes significativos de trabalhadores da produção, ocasionando o aumento do desemprego e da informalidade; o aumento da jornada e da intensificação do trabalho; a recriação

\footnotetext{
1 Trabalho financiado pelo CNPq.

* Doutor em Serviço Social pela PUC-São Paulo/Boston College. Professor Titular da Escola de Serviço Social da Universidade Federal Fluminense. E-mail: jbhg@uol.com.br

** Doutorado em Política Social pela Universidade Federal Fluminense (2014), com período de doutorado sanduíche na Universidade de Coimbra (2012-2013). Atualmente é colaboradora do Programa de Estudos Pós-Graduados em Política Social. Tem experiência como assistente social atuando nas áreas da assistência social e saúde mental, bem como na área de consultoria para empresas; e como docente em cursos de graduação e pós-graduação. Tem experiência na área do Serviço Social, com ênfase nos seguintes temas: política social, responsabilidade social empresarial, gênero, diversidade sexual e avaliação de políticas públicas. Integrante do Núcleo Transdisciplinar de Estudos de Gênero (NUTEG/UFF). Pós-doutoranda na Universidade Federal Fluminense (UFF). E-mail: teixeira.kcs27@gmail.com
} 
de formas degradantes de trabalho (trabalho infantil e trabalho análogo ao trabalho escravo); a flexibilização e precarização dos contratos de trabalho; e a fragilização do poder sindical. Essas mudanças contribuem para a perda dos direitos e para a fragmentação da classe trabalhadora, que passou a ser cada vez mais heterogênea, afetando seu poder de mobilização e suas conquistas históricas (ANTUNES, 2018).

A onda neoconservadora é igualmente indissociável da política neoliberal adotada como a resposta do capital a crise (FIORI, 1997), a qual reestruturou o papel do Estado e sua relação com o mercado e a sociedade. Tendo em vista apenas o crescimento econômico, o projeto neoliberal determinou, principalmente aos países do capitalismo tardio, um receituário divulgado pelos países imperialistas por intermédio dos organismos multilaterais, objetivando o controle dos gastos, a privatização das empresas e dos serviços públicos, a mínima intervenção dos Estados Nacionais no mercado e a divulgação da lógica mercantil (ANDERSON, 1995). Seus efeitos nefastos recaem sobre a grande maioria da população que vivencia o desemprego em massa, o aumento significativo da pobreza, da violência e a perda dos direitos de cidadania muito em função do aumento da concentração da riqueza, da flexibilização da legislação trabalhista e dos cortes de gastos com as políticas sociais, as quais passam a ser subordinadas aos interesses do capital em tempos de hegemonia liberal-financeira (IAMAMOTO, 2008). Segundo Barroco (2015, p. 626), "ao materializar-se na exploração, na dominação, na desigualdade, na violência objetiva e subjetiva, a acumulação capitalista e o neoliberalismo criaram as bases concretas para a reprodução social da barbárie manifesta em ideias, valores e comportamentos".

Tanto o padrão de acumulação capitalista, quanto a política neoliberal geraram mudanças nas esferas econômica, política, social e ideocultural. Nesta última, as mudanças foram intensificadas pela propagação do pensamento pós-moderno que invade o campo do conhecimento, a cultura e o cotidiano. Tal pensamento, ao criticar a razão moderna, os valores universais e as teorias apoiadas nas "metanarrativas", dilacerando os projetos emancipatórios (SANTOS, 2007; HARVEY, 2009), favorece a irracionalidade, a indeterminação e o abandono da crítica racional da ordem vigente (SANTOS, 2007). Tudo isso estimula experiências individualistas, fundamentalistas e irracionais de apelo à ordem em um cenário marcado pela barbárie, pelo medo e pela insegurança. É nesse contexto que o conservadorismo encontra solo fértil para a sua reatualização e se objetiva de forma moralista. Segundo Barroco (2014, p. 625), a moral passa a se constituir como a "base fundante da sociabilidade e da política".

No Brasil, o neoconservadorismo vem avançando a passos largos. Não há dúvidas que, nesse caso, é preciso considerar as particularidades da formação social brasileira (FREIRE, 2018), como o colonialismo, o racismo e os longos períodos ditatoriais, que são contributos para, sobretudo em tempos de crise, reavivar o conservadorismo e o autoritarismo. Muito em função disso deparamos-nos com a intensificação de manifestações moralistas e autoritárias no trato das expressões da questão social assumidas pelos agentes do Estado e que encontram eco na sociedade. Um exemplo é a atuação do governador Wilson Witzel, do estado do Rio de Janeiro, que comemorou com socos no ar o desfecho de uma operação policial que acabou com a morte do sequestrador de um ônibus na Ponte Rio-Niterói. Esta atitude bárbara foi aplaudida por muitos e surtiu comentários tais como: "bandido tem que ser tratado como bandido"; e "bandido bom é bandido morto"2. Este último tão em voga atualmente. Isso revela a naturalização da violência, que incide em maior grau

2 Informações disponíveis: <https://www.brasildefato.com.br/2019/08/20/witzel-comemora-morte-de-sequestrador-enquanto-policia-mata-inocentes-nas-favelas/> Acesso: 18/11/2019. 
sobre os jovens, negros, pobres, moradores de rua, mulheres e LGBTs.

Nesse contexto, a ideologia divulgada pelas classes dominantes "falseia a história, naturaliza a desigualdade, moraliza a 'questão social', incita o apoio da população a práticas fascistas: o uso da força, a pena de morte, o armamento, os linchamentos, a xenofobia" (Barroco, 2011, p. 208). Além disso, aprecia as convicções pessoais, o apelo à família, as crenças e valores tradicionais. Aciona a "moral punitiva" que supõe uma visão irracional da realidade (Barroco, 2014). Tal visão divide o mundo entre o certo e o errado; o bem e o mal; Deus e o diabo; o corruptível e o não corruptível, fazendo emergir a imagem de "mitos" que são promovidos pela mídia e pelas redes sociais por meio de fake news.

O neoconservadorismo, com seu discurso moralizante e preconceituoso, encontra legitimidade na sociedade. Esta legitimidade é construída por meio de diferentes formas repressivas de controle social, como: a repressão dos trabalhadores; a criminalização da pobreza, que gera um encarceramento em massa; a criminalização dos movimentos sociais; e a militarização da vida cotidiana. De acordo com Barroco, "essas formas de repressão implicam violência contra o outro, e todas são mediadas moralmente, em diferentes graus, na medida em que se objetiva a negação do outro: quando o outro é discriminado lhe é negado o direito de existir como tal ou de existir com as suas diferenças" (2011, p. 209).

É nesse contexto de negação do direito do outro existir com suas diferenças é que se intensificam os casos de intolerância religiosa provocados por tradições confessionais fundamentalistas e reacionárias incapazes de conviver com crenças diferentes das suas próprias. Neste artigo examinamos essa questão, conduzindo uma reflexão de casos de discriminação contra as religiões de matriz africana. Evitando uma pespectiva fatalista, também refletimos sobre as manifestações de resistência que têm se materializado contra a intolerância em questão. Ao fazê-lo refletimos também sobre as implicações da intolerância sobre a laicidade estatal - questão central para a manutenção do Estado democrático e de direito.

\section{2 - Intolerância e Violência Contra Religiões de Matriz Africana}

A intolerância religiosa - que funciona por meio da ativação de estereótipos atribuídos a um grupo discriminado - pode ser definida como a incapacidade ou ausência de desejo de respeitar crenças diferentes daquelas acolhidas por um dado indivíduo ou grupo. Um conceito desse fenômeno foi formulado por Hobolt et cols. (2011, p. 362) nos seguintes termos: (...) "a negative evaluation of a group of individuals owing to their religious affiliation (or lack thereof) and a predisposition to treat these individuals in a prejudiced manner."3 Consequentemente, (...) "the concept of intolerance is $(. .$.$) closely connected to the notion of prejudice; that is, stereotyped and negative$ beliefs about a group." Estão aí em questão o receio de riscos materiais, o medo de ameaças simbólicas associadas à presença de valores morais diferentes, as visões do "outro" como hostil e violento, os temores de desconstrução de uma identidade religiosa já consolidada etc.

Embora o discurso teológico seja a sua grande moldura, a intolerância religiosa está inserida em uma complexa teia de interesses econômicos, políticos, sociais e culturais. Abordando a

\footnotetext{
3 “(...) uma avaliação negativa de um grupo de pessoas devido a sua filiação religiosa (ou falta de tal filiação) e uma predisposição para tratar estas pessoas de forma preconceituosa (...)". [tradução nossa].

4 “(...) o conceito de intolerância é (...) umbilicalmente ligado à noção de preconceito; ou seja, crenças negativas e estereotipadas sobre um grupo”. [tradução nossa].
} 
complexidade desse fenômeno, Drake (2011) produz a seguinte problematização: "Acts performed in the name of a religion by definition have a religious component; but is religion itself the cause, or a means of expressing other grievances?" A intolerância religiosa e os seus desdobramentos sob a forma de violência é antiga e presente em diferentes formações sociais. (DRAKE, 2011; HAMAYOTSU, 2013; HOBOLT ET COLS., 2011; DOWD, 2016; SILVA e SOARES, 2015).

Um fator central motivador da intolerância em questão é a percepção que cada religião notadamente, mas não exclusivamente as da tradição cristã - têm de si mesmas. Seriam elas detentoras da verdade última e os seus membros o "povo escolhido". Elas também deteriam os mecanismos - únicos - para a obtenção da salvação, seus dogmas seriam superiores aos de outros credos e é sua função convencer ateus e adeptos de outras religiões a mudarem sua vinculação. Esta auto percepção, no máximo, permite tolerar, de forma frágil, a existência de outras crenças. Mas nunca, por vê-las como inferiores, respeitá-las pelo que elas ensinam. Em outros termos, a auto percepção em questão mantêm uma visão hierárquica que esvazia a dimensão prática do conceito de tolerância, reduzindo-a, quando muito, a uma aceitação meramente formal. A implicação concreta disso, para os credos protestantes, por exemplo, é a impossibilidade de, como afirma Silva (2015, p.77), "aceitar o discurso de que há uma única divindade que se manifesta ou age de diversas formas porque são éticas diferentes."

Às questões alinhadas até aqui associam-se outras igualmente relevantes. Uma delas é o esforço ainda existente de discriminar certas práticas religiosas minoritárias, como se vê em diferentes países . Quando isso não é possível, o pensamento intolerante busca reduzir ou mesmo eliminar a possibilidade de outros credos incorporarem novos membros e exercerem alguma influência social. Interpretações idiossincráticas da Bíblia e do Alcorão, por exemplo, são utilizadas por líderes religiosos para propagarem intolerância religiosa de diferentes tipos, muitas vezes conduzindo ao assassinato de centenas de pessoas. Ainda com base na intolerância religiosa e, ao menos em parte, devido à descrença na capacidade dos governos em resolver problemas endêmicos como a corrupção, assiste-se ao esforço de formação de Estados teocráticos.

A intensidade do conflito religioso, ontem e hoje, pode modelar grandemente a dinâmica de dada sociedade. Sobre isso, referindo-se ao caso da Nigéria, Dowd (2016, p. 622) assinala que

Falola $(1998,167)$ notes that underlying the tension between Christians and Muslims is the issue of religious dominance, who should control the state, the secular or religious character of the state, and the nature of the legal system. He even goes so far as to argue that the bitter conflicts and rivalries between Christians and Muslims have become an open, common and permanent feature of [Nigeria's] politics.6

Saliente-se que a intolerância em questão não se dá apenas entre grupos de religiões diferentes. Ela também ocorre no interior de uma mesma matriz religiosa gerando dissidências, como se vê na história do cristianismo e, mais recentemente, nas lutas internas do islamismo (DRAKE, 2011; DOWD, 2016)

A intolerância religiosa se manifesta de diferentes formas, indo desde a reprovação privada

\footnotetext{
5 "Atos realizados em nome de uma religião por definição possuem um componente religioso; mas é a religião em si a causa ou um meio de expressar outras queixas?" [tradução nossa].

6 "Falola $(1998,167)$ observa que subjacente à tensão entre cristãos e mulçumanos encontra-se a questão da dominância religiosa de quem deveria controlar o Estado, do caráter religioso ou secular do Estado e a natureza do sistema legal. Ele chega ao ponto de argumentar que os cruéis conflitos e rivalidades entre cristãos e muçulmanos se tornaram uma característica explícita comum e permanente da política da [Nigéria]." [tradução nossa].
} 
até a materialização do desejo de eliminação do outro diferente, passando por manifestações de agressão verbal, física e patrimonial. Inclui ainda a constante desqualificação dos(as) adeptos(as) do credo que é visto como inferior. Envolve também, como lembra Gualberto (2011, p. 11), "prisões ilegais, espancamentos, torturas, execuções injustificadas, negação de benefícios e de direitos e liberdades civis, agressões verbais, ataques a templos religiosos, destruição da propriedade, expulsão de seus praticantes, incitamento ao ódio (...)”.

A intolerância religiosa pode modelar processos macrossociais, a exemplo da configuração geopolítica da União Europeia (UE). Tratando desse tema, Hobolt et cols (2011) mostram como motivações religiosas - sentimentos anti-islâmicos em particular, e antirreligiosos em geral -, associadas a questões financeiras, influenciam as possibilidades de ingresso de novos países, como a Turquia, na UE, e uma descrença generalizada no futuro desse bloco político e econômico.

No Brasil, a intolerância religiosa se tornou explícita já quando da chegada, no século XVI, dos colonizadores portugueses. Uma das suas primeiras medidas foi a imposição do culto católico às populações indígenas que possuíam um acervo próprio de práticas religiosas. A celebração da primeira missa foi, ao mesmo tempo, um ato de afirmação da chegada do Cristianismo como de negação dos cultos religiosos aqui já existentes.

O advento do tráfico de escravos acentuou ainda mais a intolerância religiosa. Os negros escravizados que foram trazidos aos milhares do continente africano para o Brasil eram obrigados a adotar, ao menos parcialmente, ritos católicos, sendo negadas as condições para o culto das divindades que veneravam em seu continente de origem (REIS, 2008).

A presença da Inquisição em terras brasileiras - com a sua ação tentacular - perseguiu "dissidentes" religiosos de diferentes tipos, condenando-os ao degredo, à prisão e mesmo à morte (VAINFAS, 1997). Mesmo com o abrandamento das perseguições e com o fim da Inquisição, os ataques a religiões dissidentes continuaram. Isso foi possível, dito aqui de forma sumária, em função da ausência de separação entre a Igreja, Católica nesse caso, e o Estado. A existência de uma religião oficial no país afiançou o impedimento do exercício público de outros cultos, por vários séculos, mesmo aqueles ligados à matriz judaico-cristã, como o protestantismo (GIUMBELI, 2008).

A separação entre Igreja (Católica) e Estado estabelecida pela primeira constituição republicana, a de 1889, trouxe alterações nesse quadro, ao assegurar a liberdade de culto. Mas, mesmo assim foram mantidas restrições. A razão para tanto é que o modelo de religião para ser exercida "livremente" - o Católico - não contemplava práticas como o Espiritismo Kardecista e as de origem africana.

O Espiritismo, na transição do século XIX para o século XX, sofreu inúmeras perseguições. Contudo, porque tinha em seu meio figuras letradas, possuía uma base de apoio em camadas médias, tinha origem europeia e aproximava-se teologicamente de preceitos cristãos, foi aos poucos conquistando um lugar de maior aceitação, ou, pelo menos, manteve-se em uma zona de invisibilidade que o protegia de ataques mais virulentos. Ademais, os espíritas operavam uma rede de obras caritativas que os assemelhavam aos católicos e os inseriam na lógica colaboracionista propugnada no seio da nossa laicidade, o que o tornava mais palatável. (GIUMBELLI, 2008; JABERT, 2011). O mesmo não pode ser dito em relação às religiões de matriz africana. Essas continuaram a ser perseguidas sob diferentes alegações - charlatanismo e perturbação da ordem pública, por exemplo - que encontravam sustentação no Código Penal de 1890. Elas se distanciavam dos ideais de civilização estabelecidos e eram descritas como perigosas, devendo, portanto, serem monitoradas e combatidas. Além disso, dada sua intrínseca relação com a negritude, eram vistas como um 
elemento característico de um passado atrasado incompatível com os ideais de progresso que a nova ordem republicana buscava implantar (REIS, 2008; SILVA, 2010). Examinado essa questão, Silva e Soares $(2015$, p. 3) lembram que

mesmo com o fracasso físico do processo de "branqueamento" da identidade nacional, nasceu um novo mecanismo psicológico que manipulou o inconsciente nacional coletivo, impondo a superioridade da raça branca, sua cultura, seus valores, sua crença, seus ritos, menosprezando qualquer traço ideológico ou cultural da raça negra/mestiça. Esse processo de aculturamento rompeu a escala do tempo e persiste até os dias de hoje, sob uma prática de repulsa e intolerância àquilo que é "inferior", negando qualquer valor à cultura de outros povos não inseridos na raça "branca", com ascendência europeia.

No mesmo diapasão, Ferreti (2007, p.3) afirma que as religiões de matriz africana sofrem hoje o estigma de terem sido introduzidas no Brasil por pessoas negras, o que contribui para que sejam classificadas como bárbaras e seus sacerdotes serem "frequentemente apontados como atores ou insufladores de práticas criminosas, ilegais ou repudiadas socialmente (assassinatos, práticas ilegais de medicina etc.)." Silva e Soares (2015) também asseveram que ao ódio racial soma-se o preconceito de classe dada a predominância de pretos e pardos nos segmentos mais pobres da população os quais, por sua vez, constituem a maioria dos adeptos dos cultos afro-brasileiros. Em suma, a intolerância contra as religiões de matriz africana opera em uma complexa intersecção de classe e raça, além de orientação sexual, dada a conhecida grande presença, como mostrou Ruth Landes (2002), de gays e lésbicas entre seus adeptos.

Em função dessa complexa intersecção de vulnerabilidades, para continuarem a existir de forma institucionalizada as religiões em questão tiveram, durante décadas, que se submeter a regramentos os mais diversos, notadamente a necessidade de registro dos seus templos em delegacias de polícia às quais deveriam reportar e obter autorização para a realização das suas atividades. Esse procedimento, todavia, não impedia a suspensão arbitrária de seus cultos e a criminalização dos seus adeptos.

Ao longo do século XX a perseguição policial teve continuidade, sempre amparada legalmente no texto constitucional e, principalmente, no Código Penal. Apesar disso, a literatura especializada aponta que a partir das décadas de 1950 e 1960 tal perseguição, ainda que nunca tenha desaparecido, vinha arrefecendo. Contribuiu para isso, dentre outros fatores, o crescente interesse de intelectuais e artistas famosos pelo candomblé (MORAIS, 2012). Referindo-se a essa quadra histórica, Silva (2010, p. 5) afirma que: "Determinadas casas, principalmente as que se tornaram 'objetos da ciência', foram mais toleradas (...). Afinal, eram locais onde passavam o Dr. Bastide, Dr. Carneiro, Dr. Gilberto Freyre, dentre outros."

Contudo, em um movimento de idas e vindas, a partir da década de 1980, os grupos religiosos de matriz africana começaram a enfrentar uma nova onda sistemática de intolerância - aquela vinda de igrejas ligadas ao protestantismo, notadamente do seu ramo neopentecostal (SILVA, 2010; SILVA, 2015) - com desdobramentos práticos substanciais.

Esse fenômeno está associado, dentre outros fatores, a mudanças no próprio campo evangélico. Resumidamente, tal campo, a partir daquela década, passou a enfatizar novos elementos do seu arcabouço teológico e pragmático. Um deles é a ideia de "teologia da prosperidade”. Tal teologia, reduzindo a dimensão ascética do protestantismo, enfatiza a conquista de bens e sucesso material na terra como uma das formas de evidenciar a vinculação com Deus. Não é mais suficiente obter a salvação no reinodos céus, mas também ter uma vida próspera materialmente aqui na terra. 
Para tanto é necessário dar materialidade à "batalha espiritual" contra as "forças ocultas" que impedem a felicidade dos homens e mulheres. Os demônios bíblicos, em tal batalha, continuam a ser combatidos, mas se devem também enfrentar as entidades - exus, pombas-gira, orixás, inquices etc. - oriundas das religiões de matriz africana. São essas entidades que estariam gerando doenças, causando desavenças familiares e obstaculizando o progresso material e espiritual dos fieis das igrejas evangélicas, necessitando ser, portanto, combatidas. Isso requer uma atitude mais proativa por parte das igrejas evangélicas que envolvem duas formas de ação (ORO, 2003). ${ }^{7}$

A primeira delas é a ênfase em práticas proselitistas, com as quais busca-se, através de diferentes meios de persuasão, aumentar o seu número de fieis (SILVA, 2007). A segunda é a destruição, simbólica e material, dos grupos religiosos de matriz africana. O proselitismo tem se dado por meio de promessas de cura de doenças graves; de resolução de conflitos familiares, principalmente os matrimoniais; da prosperidade financeira; e da "libertação" das "forças diabólicas" personalizadas nas divindades do panteão afro-brasileiro.

Já a destruição simbólica e material dos grupos religiosos de matriz africana vem ocorrendo através de potentes campanhas de difamação, as quais são feitas, além dos púlpitos das igrejas, através do complexo midiático que as igrejas evangélicas lograram construir ao longo dos anos. Por meio dos seus jornais impressos e online, de livros, panfletos e programas de televisão, elas difundem imagens derrogatórias sobre as religiões de matriz africana e seus adeptos (SILVA, 2007). Um inventário feito a partir de notícias veiculadas em jornais de grande circulação mostra um grande rol de falsas acusações dirigidas a casas religiosas de matriz africana: sequestro de crianças; manutenção de pessoas em cárcere privado; sacrifício de seres humanos; propagação de doenças graves etc. (GUALBERTO, 2011).

As campanhas difamatórias têm sido acompanhadas de outras formas de ações violentas, a exemplo da invasão de terreiros e destruição do seu patrimônio material. ${ }^{8}$ Verifica-se também a imposição de dificuldades para a realização das práticas rituais. Uma das estratégias utilizadas para tanto é a colocação de carros de som em frente aos terreiros por longas horas e interrupção forçada de rituais. Outra é a tentativa de criminalizar as práticas rituais de sacrifício animal. ${ }^{9}$ Soma-se a isso a agressão física dos adeptos dentro e fora dos seus locais de culto e a exposição dos mesmos, inclusive crianças, a situações de constrangimento em espaços coletivos como nas escolas e nos transportes públicos (CAPUTO, 2012). Registre-se também aqui os esforços de apropriação e deformação de símbolos afro-brasileiros, religiosos ou não. Dois exemplos disso são a chamada "capoeira gospel” e o "acarajé de Jesus". No limite, como tem sido amplamente divulgado na mídia, pastores associam-se a membros do tráfico de drogas para expulsar os chefes dos terreiros do seu local de culto e proibir os moradores de uma dada região de expressar publicamente qualquer forma de filiação (usar roupas brancas e fios de contas; acender velas; entoar determinadas cantigas etc.) às crenças afro-brasileiras (CUNHA, 2014).

Não casualmente que dados do Centro de Promoção da Liberdade Religiosa e Direitos Humanos apontem que das 948 denúncias de intolerância religiosa recebidas entre 2012 e 2014,

\footnotetext{
7 A agenda neopentecostal em particular e a evangélica em geral ganhou ainda mais força porque aos elementos já citados foi feito um grande e bem-sucedido investimento na política partidária. Tal investimento tem levado à eleição de muitos parlamentares vinculados ao campo evangélico.

8 Disponível em <https://brasil.elpais.com/brasil/2017/11/03/politica/1509708790_213116.html>. Acesso: 14/07/2020.

9 Disponível em < https://g1.globo.com/politica/noticia/2019/03/28/stf-decide-que-e-constitucional-sacrificar-animais-em-cultos-religiosos.ghtml> Acesso: 14/07/2020.
} 
71\% eram de ofensas contra religiões de matriz africana. (SILVA e SOARES, 2015).

Denúncias como essas não são recentes. Com efeito, há que se lembrar que, em maior ou menor frequência, nunca deixaram de existir. Chama atenção, contudo, que as respostas policiais, quando ocorrem, muitas vezes são inócuas, as punições raras e as denúncias, com inusitada frequência, abordadas com desdém ou vistas como problemas menores que devem ser tratadas no âmbito das relações privadas, como as de vizinhança. Isso, em parte, é produto da incapacidade do aparato policial e judicial de lidar com a questão (MIRANDA, 2009).

A ausência de respostas adequadas já não tem sido recepcionada de forma passiva pelas religiões afro-brasileiras. Ao contrário, é possível dizer que elas estimularam estratégias de respostas coletivas de diferentes envergaduras, como examinaremos a seguir.

\section{3 - Resistência e Organização das Religiões de Matriz Africana}

A exploração dos trabalhadores da nascente indústria brasileira na transição do século XIX para o século XX foi acompanhada de inúmeros movimentos grevistas; a escravidão não se deu sem a rebelião de negros e negras; e as formas cotidianas de violência contra mulheres e LGBTs encontram diferentes formas de resistência. Esses exemplos são indicadores de que, em geral, os processos de opressão, nas suas diferentes expressões, ontem e hoje, são geralmente acompanhados de formas de resistência, mesmo em contextos de grande adversidade. A violência e a intolerância religiosa contra o campo afro-brasileiro não constituem exceções.

Em função disso, ao longo da nossa história vemos modos de resistência micropolítica e macropolítica. Esse segundo modo tem assumido diferentes formas em todos os estados da federação. Tratam-se de caminhadas e protestos que objetivam denunciar a violência sofrida e pregar umacultura da paz; apresentação de requerimentos às autoridades competentes; formação de entidades voltadas à defesa dos interesses do segmento religioso afro-brasileiro; apresentação de queixas-crime; protestos de políticos; articulação com entidades ecumênicas; realização de seminários e congressos; publicação de livros; criação de programas de rádio e televisão; vinculação a entidades do movimento negro etc.

Ao mesmo tempo, têm sido implementados projetos de valorização da cultura e religião afro- brasileira, a exemplo daqueles voltados à preservação e ensino da língua yorubá; das inúmeras oficinas de valorização da aplicação dos conhecimentos afro-brasileiros para a saúde; da capacitação do povo de santo para as práticas de controle social de políticas públicas etc. (CAPUTO, 2015; GOMES, 2010; SILVA, 2007). ${ }^{10}$

Destaque-se também a formação de redes de terreiros para a realização de trocas de experiências. Essa, em uma análise preliminar, não é uma tarefa fácil, pois os cultos afro-brasileiros apresentam divergências e diferenças de forma e de fundo entre si, e

(...) têm se desenvolvido muito mais por dissidências e contraposições do que por aglutinação em torno de entidades de representação coletiva. O modelo de organização federativa dos centros espíritas, por exemplo, foi adotado com relativo sucesso pelos terreiros de umbanda, mas pouca influência teve entre os de candomblé. (SILVA, 2007, p.223).

\footnotetext{
10 Embora nos refiremos aqui a essas formas de resistência no tempo presente, é digno de nota as ações de resistência, muitas das quais contaram com o auxílio de intelectuais articulados com figuras proeminentes do candomblé já na década de 1930 (SILVA, 2010; MORAIS, 2012).
} 
Muitas dessas experiências são de caráter local e de curta duração. Ademais, enquanto algumas delas mostram-se, em uma análise preliminar, efetivas; outras não geram resultados nem mesmo próximos dos esperados. Apesar disso, não consideramos uma hipótese desarrazoada pensar que elas impulsionaram a politização do segmento religioso afro-brasileiro e fomentaram formas mais amplas de mobilização coletiva voltadas para a atuação na esfera pública.

Esse conjunto de ações estimulou a negociação de um lugar na agenda social ${ }^{11}$, notadamente a governamental, para a reflexão e defesa dos seus interesses e direitos. A expansão das ações da sociedade civil de combate à intolerância contra as religiões de matriz africana foi, assim, acompanhada da criação de estruturas governamentais com objetivos similares. Levantamento inicial feito mostra a presença, em diferentes estados da federação, de estruturas administrativas voltadas a lidar com tal intolerância. Elas têm desenhos institucionais variados e detêm capitais distintos. Outrossim, nem sempre perduraram por muito tempo, já que estão sujeitas às intempéries do jogo político-partidário. No governo federal, embora não tratasse apenas da intolerância contra as religiões de matriz africana, destaca-se a Secretaria Especial de Políticas de Promoção da Igualdade Racial (SEPPIR). Ela foi criada em 2003, durante o primeiro mandato do presidente Luís Inácio Lula da Silva, tendo sido totalmente desmantelada quando da chegada de Michel Temer à presidência da república.

Entre avanços e retrocessos, em suma, é factual que diferentemente do que ocorria até a década de 1970, quando o Estado ainda reprimia as religiões de matriz africana, hoje ele tem "uma postura diferente uma vez que o governo brasileiro, em suas diferentes esferas de poder, desenvolve ações que contemplam em alguma medida as religiões que já foram consideradas por ele uma contravenção.” (MORAIS, 2012, p.41)

É fundamental destacar que a intolerância contra as religiões de matriz africana (nas suas intersecções com raça, classe e orientação sexual) não é um fenômeno que se encerra em si mesmo. Ela diz respeito e se conecta à complexa questão da laicidade do Estado e do estágio de desenvolvimento da democracia e o impacto dessas duas variáveis na vida dos diferentes segmentos de nossa sociedade.

\section{4 - Intolerância Religiosa, Laicidade e Democracia: a guisa de con- clusão}

O projeto da modernidade e da democracia pressupõe uma crescente secularização da sociedade, o que implicaria na redução da influência religiosa sobre as relações sociais. Isso, ao seu turno, permitiria a desvinculação de qualquer credo religioso das estruturas estatais, gerando o que se convencionou chamar de "Estado laico". Em tal projeto, obter- se-ia uma privatização da religião, ficando a legitimidade da mesma, como propugna o filósofo Richard Rorty (1999), circunscrita ao âmbito dos templos e das famílias. Em

função disso, os "negócios públicos" seriam resolvidos sem a interferência (ou com uma interferência mínima) de particularismos religiosos. ${ }^{12}$

\footnotetext{
11 De modo simplificado, a agenda pode ser definida como o local no qual são inscritos os problemas considerados objeto de intervenção governamental e não-governamental.

12 Secularização, laicidade e privatização não equivalem, dentro de diversas tradições teóricas e políticas, à eliminação ou perseguição das religiões existentes. Ao contrário, implica na sua proteção e no tratamento igualitária a ser dado a todas elas.
} 
Muitos pensadores acreditam que a sustentação do Estado moderno e da democracia, notadamente os direitos civis e políticos, pode ser associada a um alto grau de privatização do mundo religioso. Pierucci (2008, p.12), por exemplo, discutindo essa questão, afirma que

só teremos a ganhar, tanto no plano teórico quanto no prático, se voltarmos a pensar que $a$ secularização que importa em primeiro lugar - a secularização que nos concerne imediatamente, seja enquanto estudiosos, seja principalmente enquanto cidadãos-sujeitos-de-direitos empenhados em preservar e ampliar as liberdades civis e políticas de cada um e de todos "sob domínio da lei" num "Estado democrático de direito", interessados praticamente, portanto, e não só teoricamente, na observância universalizadas de leis revisáveis porque não mais divinamente reveladas - a secularização que importa antes de tudo, repito, é a secularização do Estado como ordem jurídica. Noutras palavras, a laicização constitucional disto que a conhecida definição de Kelsen denomina Estado formal.

A ideia moderna de laicidade estatal não implica na eliminação das religiões nem tampouco em uma postura antirreligiosa por parte do Estado. Implica, sim, na equidistância do Estado em relação aos diferentes credos, não assumindo qualquer um deles como oficial. Isso o força a respeitar todos os cultos e a não intervir nas suas dinâmicas internas. Assim, por mais religiosa que seja a sociedade, o Estado estará preparado para garantir a convivência pacífica entre os diferentes credos e, ao mesmo tempo, impedir o transbordamento das suas leituras particularistas para a regulação da vida coletiva e dos valores acordados fora da esfera eclesiástica.

No que pese o valor desses raciocínios, não se pode esquecer que eles apresentam limites próprios a qualquer pensamento prescritivo. Isso equivale a dizer que na esfera das relações materiais e simbólicas de nossas sociedades a religião sempre está presente.

Se isso é verdade, a laicidade estatal não pode ser tratada como um elemento absoluto inscrito em uma antinomia composta pela sua total "existência" ou total "inexistência". Ao contrário, a laicidade é uma questão de "grau". Ou seja, ela sempre existirá em maior ou menor intensidade em Estados e sociedades em função das diferentes correlações de forças nelas presentes.

Tratando-se de um processo social bastante dinâmico, não é possível estabelecer um quantum de laicidade possível e desejável. Ademais, pelo que nos ensina a história - aquela das relações reais entre os indivíduos -, mesmo em sociedades muito secularizadas e Estados bastante laicizados, nunca se conseguiu que as diferentes denominações religiosas se mantivessem totalmente silentes em relação a matérias de interesse público (PORTIER, 2011). A rigor, do ponto de vista teórico, como lembra Oro (2003, p. 64),

malgrado a separação oficial entre Igreja e Estado, a história das relações entre política e religião (...) sugere menos a existência de autonomia e oposição entre esses campos do que de continuidade, ponte, trânsito e passagem, o que resulta na dificuldade de se traçar fronteiras claras.

O curso da história mostrou que as expectativas do ideário da modernidade e dos teóricos contemporâneos não se materializaram plenamente, nem tampouco têm seguido uma trajetória linear. Ao contrário, assistimos ao longo do século XX e nos dias atuais a uma contra secularização e a tomada, formal ou simbólica, total ou parcial, das estruturas estatais por agentes religiosos.

É o que aconteceu, por exemplo, no Irã, na passagem da década de 1970 para a década de 
1980. A ascensão de um líder religioso - o Aiatolá Khomeini - ao poder resultou na eliminação dos direitos de manifestação e no assassinato de muitos opositores. (GHOLIZADEH e HOOK, 2012).

A Indonésia constitui outro exemplo emblemático desse processo. Esse país reinstaurou a democracia em 1998, revitalizando as instituições e procedimentos de participação popular, o que abriu a possibilidade de a sociedade civil expressar as suas demandas e objeções de ordem política e cultural.

\begin{abstract}
At an early stage during the democratic transition, liberal groups and observers were indeed, hopeful and celebrated the democracy and freedoms that Indonesia finally gained.

Muslim liberals were almost certain that media freedom and new media, alongside other freedoms finally granted, would facilitate religious plurality and a fragmentation of religious authority so as to encourage new types of religious intellectuals and authority to emerge and thrive. (HAMAYOTSU, 2013, p. 662). ${ }^{13}$
\end{abstract}

Isso, contudo, não ocorreu e nem foram imobilizadas as correntes que desejam a teocratização do Estado indonésio, as quais têm dado curso à expansão dos conflitos religiosos decorrentes da intolerância. Ao contrário, mesmo em um contexto de redemocratização e maior liberalização do acesso aos meios de comunicação, foram os setores mais sectários do Islamismo, que - em um processo semelhante ao que ocorre no Brasil - veem se apropriando dos antigos e novos mass media, ocupando agências estatais, modelando políticas públicas e associando-se a políticos detentores de grande volume de recursos financeiros. O resultado imediato dessa conjunção de fatores é a acentuação do conservadorismo e do radicalismo islâmico e da sociedade indonésia como um todo, o que, obviamente, favorece o conflito religioso. (HAMAYOTSU, 2013).

Ainda mais emblemático é o caso do Afeganistão. Com sua política formalmente fundada em cânones religiosos, o regime ali instituído elimina, por via da pena demorte, aqueles que se opõe ao sistema ou infringem normas religiosas. (FARREL e GIUSTOZZI, 2013).

Mesmo países de maior tradição laica e democrática também organizam políticas a partir de argumentos religiosos. Veja-se o caso dos Estados Unidos na sua política internacional e nas guerras declaradas contra países como o Iraque. Analistas mostraram que, além dos interesses econômicos, foram ali considerados argumentos neoconservadores de cariz religioso.

No Brasil, também é claramente perceptível o transbordamento do campo religioso e a sua incidência na vida pública, inclusive nas arenas políticas formais. Tal transbordamento, na história recente, não tem se dado de forma discreta. A criação, em 2003, da Frente Parlamentar Evangélica (FPE) na Câmara Federal, é um exemplo claro disso. A FPE, maior e ainda em operação nos dias de hoje, tem como objetivo gestar formas de oposição ao que considerar uma violação das leis naturais e da moral cristã. Como bem lembra Duarte (2012, p. 54), as atividades da FPE constituem verdadeiros cultos dentro do Congresso Nacional, representando "a transformação do espaço de feitura de leis num espaço de invocação do religioso e de sacralização da política.” Portanto, há motivos ponderáveis para se temer que o grau de influência do campo religioso cristão nas matérias de interesse público esteja se alastrando demasiadamente rápido e sem mecanismos eficazes que

13 "Em um estágio inicial, durante a transição democrática, grupos liberais e observadores estavam esperançosos e celebraram a democracia e as liberdades que a Indonésia tinha finalmente obtido. Muçulmanos liberais estavam quase convencidos que a liberdade de imprensa e os novos meios de comunicação, em conjunto com outras expressões de liberdade finalmente asseguradas, poderiam facilitar a pluralidade religiosa e uma fragmentação da autoridade religiosa capaz de encorajar o florescimento de novos tipos de intelectuais e autoridades religiosas." [tradução nossa]. 
possam colocar freios a tal alastramento. Isso, a nosso ver, pode trazer sérios comprometimentos à nossa democracia, notadamente aos direitos sociais e às liberdades civis, pois cada vez mais discursos formulados a partir de interpretações teológicas e exegeses bíblicas particular e adentramos os espaços formais da política através dos parlamentares cristãos. O deputado federal Hidezaku Takayama (PSC/PR), por exemplo, em discurso na Câmara de Deputados, procurou conciliar a sua defesa de valores cristãos, com o direito de expressão religiosa e um modelo heteronormativo de "família brasileira" nos seguintes termos:

(...) E não me venham com a conversa de dizer que o Brasil é laico. O Brasil não é laico. $\mathrm{O}$ Governo é laico, mas o país é cristão. Nós entendemos que, neste Parlamento, as minorias têm todo o direito de falar, e essa é a beleza da democracia, mas também não podemos abrir mão de respeitar a grande maioria brasileira, que é uma maioria cristã. (...) estendi [entendi] que esse Brasil está certo em assumir Jesus como o salvador de suas vidas. E eu defendo, portanto, os valores cristãos. (...) É importante nós dizermos que somos favoráveis aos valores da família. Eu não estou aqui porque dois homens se amaram. Você, que está me ouvindo, não está aí porque duas mulheres ou dois homens se amaram. Família é muito mais coerente. E não quero ser tachado de fundamentalista, ou coisa parecida, mas é muito mais coerente eu entender que eu estou aqui porque um homem e uma mulher constituíram uma família e, pelo seu amor, eu fui concebido. Agora, dois homens ou duas mulheres jamais vão gerar um ser. ${ }^{14}$

A intervenção religiosa nos espaços políticos não tem se dado apenas através de discursos como este transcrito acima. Ela também se desdobra na ocupação de posições estratégicas no legislativo, como se viu na eleição do deputado federal Pastor Marco Feliciano (PSC/SP), à presidência da Comissão de Direitos Humanos e Minorias (CDHM), em 2013. Contando com o apoio de diversos líderes evangélicos, a gestão do deputado Pastor Marco Feliciano à frente da CDHM foi marcada pelo encaminhamento e, às vezes, aprovação de medidas regressivas dos direitos das minorias. ${ }^{14}$ Dentre outras propostas que encaminhou estava aquela que pretendia tornar sem efeito uma resolução do Conselho Federal de Psicologia que proibia a atuação de psicólogos em eventos e serviços que propunham tratamento e cura da homossexualidade. Conseguiu também aprovar proposta de convocação de plebiscito sobre a união entre pessoas do mesmo sexo e sobre a resolução do Conselho Nacional de Justiça (CNJ) que obriga cartórios a validar casamentos de homossexuais, ambas posteriormente derrubadas no plenário da Câmara dos Deputados. ${ }^{15}$

A bancada cristã (principalmente o seu segmento evangélico-pentecostal) busca, simultaneamente, um espaço cada vez maior de intervenção em todas as esferas da administração pública e a redução da livre expressão de outros credos. Isso, atualmente, é bastante evidente em relação aos cultos de matriz africana. ${ }^{10} \mathrm{O}$ fazem, vale reiterar, através de campanhas difamatórias e de ameaças verbais. Tal fato coloca em pauta questões fundamentais sobre as noções de igualdade e democracia em nossa sociedade que extrapolam o campo estritamente religioso. Quem são os iguais entre nós? Como a sociedade brasileira se constituiu de modo a permitir que ainda hoje existam estratificações tão acentuadas no plano dos direitos de primeira geração, a exemplo dos direitos civis?

14 Disponível em <https://www.camara.leg.br/internet/sitaqweb/TextoHTML.asp?etapa=3\&nuSessao=0 47.4.54.0\&nuQuarto $=23 \&$ nuOrador $=3 \&$ nulnsercao $=0 \&$ dtHorarioQuarto $=10: 06 \&$ sgFaseSessao $=\mathrm{GE} \% 20$ \%20\%20\%20\%20\%20\%20\%20\&Data=14/03/2014\&txApelido=TAKAYAMA\&txFaseSessao=Grande $\% 20$ Expediente\%20\%20\%20\%20\%20\%20\%20\%20\%20\%20\%20\%20\%20\&dtHoraQuarto=10:06\&txEtapa= com\%20reda\%C3\%A7\%C3\%A30\%20final> Acesso em 14/07/2020.

15 Ainda que em grau bem menor, os templos católicos têm também sido alvos de ataques virulentos de evangélicos. 
Aos esforços de depreciação das religiões de matriz africana que têm lugar no parlamento, somam-se aqueles que ocorrem em outros espaços. Como afirmamos anteriormente, a partir da década de 1990 a perseguição contra essas religiões recrudesceu reabilitando velhos argumentos de que os cultos afro-brasileiros não podem ser considerados religiões, ao menos não equiparáveis ao catolicismo e ao protestantismo. A partir de então, devido a uma estranha aliança entre evangélicos, alguns agentes estatais e facções criminosas, umbandistas e candomblecistas passaram a vivenciar formas muito violentas de perseguição. Uma perseguição que pode ser chamada informal e que ocorre no plano cotidiano através das intimidações as mais diversas (ameaças, invasão dos terreiros, proibição de realização de rituais, segregação dos fieis impedindo-lhes o acesso a bens e serviços etc.). Mas também uma perseguição de natureza mais formal, operada por segmentos da burocracia estatal, ou seja, a mesma burocracia que é corresponsável pela garantia da efetividade do princípio do tratamento isonômico para todas as religiões.

Um comentarista, que é também militante, constata que na cidade de São Paulo ainda hoje nenhum templo de candomblé tem assegurada a imunidade tributária, os ministros não conseguem obter inscrição no sistema de seguridade social e os cartórios se recusam a reconhecer a validade dos casamentos realizados no candomblé. (GIUMBELLI, 2008, p. 85).

A perseguição às religiões de matriz africana, por envolver a ação de grupos religiosos e pela participação ou omissão estatal, serve para chamar a atenção para os riscos reais e potenciais da redução da laicidade em nosso país hoje. Aprofundar o entendimento desse processo com vistas à sua superação é fundamental para a consolidação democrática do Estado e nação brasileiros.

\section{5 - Referências}

ANDERSON, P. Balanço do neoliberalismo. In: SADER, E.; GENTILI, P. Pós-neoliberalismo: as políticas sociais e o Estado democrático. Rio de Janeiro, Paz e Terra, 1995:09-28.

ANTUNES, R. O privilégio da servidão. São Paulo, Boitempo, 2018.

BARROCO, M. L. Não Passarão! Ofensiva neoconservadora e Serviço Social. Serviço Social e Sociedade, n. 124, p. 623-636, out/dez., 2015.

BARROCO, M. L. Barbárie e neoconservadorismo: os desafios do projeto ético-político. Serviço Social e Sociedade, v. 106, p. 205-218, 2011.

CAPUTO, S. G. Educação nos terreiros e como a escola se relaciona com crianças de candomblé. Rio de Janeiro: Pallas, 2012.

CAPUTO, S. G. Learning yorubá through educational networks in candomblé communities: history, African culture and confronting intolerance in schools. Revista Brasileira de Educação, vol. 20, n. 62, 2015.

CUNHA, C. V. Religião e criminalidade: traficantes e evangélicos entre os anos 1980 e 2000 nas favelas cariocas. Religião e Sociedade, vol.34 n.1. Rio de Janeiro, Junho, 2014.

DRAKE, H.A. Intolerance, religious violence and political legitimacy in late antiquity. Journal of the American Academy of Religion, vol 79, n.1, 2011.

DUARTE, T.S. A participação da Frente Parlamentar Evangélica no Legislativo Brasileiro: ação política e (in)vocação religiosa. Ciências Sociais e Religião, vol. 14, n.17, 2012.

FARRELL, T. e GIUSTOZZI, A. The Taliban at war: inside the Helmand insurgency, 2004-2012. International Affairs, vol. 89, N. 4, 2013.

FERRETTI, M.M.R. Religião e sociedade: religiões de matriz Africana no Brasil: um caso de polícia. Anais da III Jornada Internacional de Políticas Públicas. São Luis, 2007.

FIORI, J. L. Estado de Bem-Estar Social: Padrões e Crises. PHISIS. Revista Saúde Coletiva. 7(2). 
Rio de Janeiro, 1997:129-147.

GHOLIZADEH, S.; HOOK, D. Journal of Community \& Applied Social Psychology, vol 22, 2012.

GIUMBELLI, E. A presença do religioso no espaço público: modalidades no Brasil. Religião e Sociedade, v.28, n.2, 2008.

GOMES, M.C.P.A. Projeto: Ylê ayié yaya ilera (saúde plena na casa desta existência): equidade e integralidade em saúde para a comunidade religiosa afro-brasileira. Interface, vol.14, n.34, 2010.

GUALBERTO, M.A.M. Mapa da intolerância religiosa-2011. São Paulo: AAMAP, 2011.

HAMAYOTSU, K. The limits of civil society in democratic Indonesia: media freedom and religious intolerance.

HARVEY, D. Condição pós-moderna: uma pesquisa sobre as origens da mudança cultural. 11. ed. São Paulo: Loyola, 2009.

HOBOLT, S. B ET COLS. Religous intolerance and Euroscepticism. European Union Politics, vol. 12, n. 3, 2011.

IAMAMOTO, M. V. Serviço social em tempo de capital fetiche: capital financeiro, trabalho e questão social. 3. ed. São Paulo: Cortez, 2008.

LANDES, R. 2002. A Cidade das Mulheres. Rio de Janeiro: Editora da UFRJ.

MIRANDA, A.P.M. Entre o privado e o público: considerações sobre a (in)criminação da intolerância religiosa no Rio de Janeiro: Anuário Antropológico, 2010.

MORAIS, M.R. Políticas públicas e a fé afro-brasileira: uma reflexão sobre ações de um Estado laico. Ciências Sociais e Religião, vol. 14, n. 16, 2012.

ORO, A.O. A política da Igreja Universal e seus reflexos nos campos religioso e político brasileiros. Revista Brasileira de Ciências Sociais, vol.18, n.53, 2003.

PIERUCCI, A. F. De olho na modernidade religiosa. Tempo Social, vol.20, n.2, 2008.

PIRES, M.I.S. A assistência social na Igreja Católica no espaço do terceiro setor - inserção e repercussões ídeo-políticas. (Tese de Doutorado - Serviço Social). PUC/SP, 2004.

PORTIER, P. A regulação estatal da crença nos países da Europa Ocidental. Religião e Sociedade, vol.31, n.2, 2011.

REIS, J.J. Domingos Sodré, um sacerdote africano: escravidão, liberdade e candomblé na Bahia do século XIX. São Paulo: Companhia das Letras, 2008.

RORTY, R. Religion as a conversation-stopper. In: R. Rorty. Philosophy and social hope. New York: Penguin Books, 1999.

SANTOS, J. S. Neoconservadorismo pós-moderno e Serviço Social brasileiro. São Paulo: Cortez, 2007.

SILVA, B. R. da. Sob o signo de Cam: as lutas da tradição religiosa de matriz africana contra a intolerância no Brasil republicano. Anais do $7^{\circ}$ Congresso Ibérico de Estudos Africanos, Recife, 2010.

SILVA, C.A. Desafios e propostas para promoção do reconhecimento da diversidade religiosa no Brasil. Estudos de Religião, vol.29, n.2, 2015.

SILVA, J.M. da. Religiões e saúde: a experiência da Rede Nacional de religiões afro- brasileiras e saúde. Saúde e Sociedade, vol. 16, n. 2, 2007.

SILVA, L.C. da e SOARES, K. dos R. A. A intolerância religiosa face às religiões de matriz africana como expressão das relações étnico-raciais brasileiras: o terreno do combate à intolerância no município de Duque de Caxias. Revista Educação, vol. 01, n.03, 2015. 